\title{
Elastic modulus evaluation of Titania nanotubes obtained by anodic oxidation
}

\author{
Luciane S. Santos ${ }^{1}$, Nilson T. C. Oliveira ${ }^{2}$, \\ Carlos M. Lepienski ${ }^{1}$, Cláudia E. B. Marino ${ }^{1}$, Neide K Kuromoto ${ }^{1,3}$
}

\author{
${ }^{1}$ Graduate Program in Engineering and Materials Science - PIPE - UFPR CP: 19011 - 81531-990, Curitiba, PR \\ e-mail: luciane.santos@ufpr.br \\ ${ }^{2}$ Department of Materials Engineering - DEMa - UFSCAR CEP: 13565-905, São Carlos, SP \\ e-mail: ntco@yahoo.com \\ ${ }^{3}$ Physics Department - UFPR - CP: 19044 - 81531-990 Curitiba, PR \\ e-mail: kuromoto@ fisica.ufpr.br
}

\begin{abstract}
The use of titania $\left(\mathrm{TiO}_{2}\right)$ nanotubes is becoming one of the most attractive techniques as surface treatment for implants due its combination of morphology (that accelerates osteoblast adhesion and proliferation), bioactivity and possibility of being use as a drug vehicle. Anodic oxidation is one of the cheapest and simplest approaches to obtain highly ordered nanotubes. Parameters such as applied potential, reaction time and fluoride containing in the electrolyte define the nanotubes morphology. However, the mechanical properties of the nanotubes layer do not have been completely elucidated and they play a crucial role in the implant long term stability. The objective of this research was to obtain $\mathrm{TiO}_{2}$ nanotubes using anodic oxidation and to determine their elastic modulus and hardness. The $\mathrm{TiO}_{2}$ nanotubes layer was obtained in a fluoride containing electrolyte for 1 hour, one group at $15 \mathrm{~V}$ and another one at $25 \mathrm{~V}$. The $\mathrm{TiO}_{2}$ nanotubes morphology was characterized by scanning electron microscopy (SEM) and atomic force microscopy (AFM). The elastic modulus and hardness were evaluated by nanoindentation experiments using a spherical tip. SEM images showed highly ordered nanotubes on all titanium surfaces and it was observed that the nanotubes diameters are directly related with the applied potential. Nanotubes diameters are $66 \pm 9 \mathrm{~nm}$ and $131 \pm 22 \mathrm{~nm}$ for nanotubes obtained at $15 \mathrm{~V}$ and $25 \mathrm{~V}$, respectively. Nanoindentation test results showed a decrease in the elastic modulus comparing with titanium reference and these values approach to cortical bone elastic modulus. These results demonstrate that it was possible to obtain a homogeneous $\mathrm{TiO}_{2}$ nanotubes layer that has mechanical properties adequate to improve implant long-term stability.
\end{abstract}

Keywords: Titania nanotubes, anodic oxidation, indentation, elastic modulus.

\section{INTRODUCTION}

Titanium and titanium alloys are the materials most used as endosseous implants. Their characteristics as mechanical properties, low density, good corrosion resistance, make them more attractive than other used as implants, as stainless steel $316 \mathrm{~L}$ and Cr-Co alloy [1], [2]. Elastic modulus (E) is a property that affects directly the implant stability. It is desirable that the metal elastic modulus be as close as possible from that of the bone (around $30 \mathrm{GPa}$ to the cortical bone), because lower differences between the E values result in better transfer of stress, avoiding stress-shielding effect [3]. Being a valve metal, titanium has a self-formed spontaneous oxide layer that prevents the release of ions when implanted, leading to biocompatibility. However this thin oxide layer does not promote chemical bonds with live tissue, so it's necessary a surface treatment to improve their surface properties looking for a optimized osseointegration [4].

Recently, $\mathrm{TiO}_{2}$ nanotubes are being studied as a surface treatment due to the combination of $\mathrm{TiO}_{2}$ properties and the nanotubular morphology. Researches demonstrate that the nanotubes accelerate osteoblast adhesion and growth [5], enhance apatite deposition [6], exhibit excellent bioactivity [7], improve bone bonding in vivo [8], demonstrate better corrosion resistance [9] and can be a drug delivery vehicle [10]. $\mathrm{TiO}_{2}$ nanotube layer can be produced by many methods, including template-assisted methods, sol-gel techniques, and hydro/solvothermal methods (with or without templates) [11]. Among these different superficial treatment the simplest and cheapest approach is the anodic oxidation using hydrofluoric containing electrolyte [12]. 
Elastic modulus of $\mathrm{TiO}_{2}$ nanotubes layer is not well established until now and it plays an important role on the long term stability of the implant, although few researches have investigate it. Instrumented indentation is the most suitable technique to determine the elastic modulus of thin films, however the initial roughness and the probe geometry can impose some limitations. Crawford [13] has examined the deformation behavior of a nanotube layer using nanoindentation tests with a Berkovich probe, what led to a indentation penetration higher than the thickness of the nanotube layer and wear marks on indentation.

In this study it is reported the nanotube obtainment under two different potentials, to observe their morphological properties and investigate the elastic modulus of $\mathrm{TiO}_{2}$ nanotubes layers using a spherical probe .

\section{MATERIALS AND METHODS}

Prior to anodic oxidation, commercially pure titanium samples $(\sim 5 \times 18 \times 2) \mathrm{mm}$, grade 2 were grounded and polished with $\mathrm{SiC}$ paper and silical coloidal suspension to mirror image. They were then degreased by sonicating in acetone, isopropyl alcohol and deionized water, for $15 \mathrm{~min}$ in each bath. To remove the air-formed oxide layer the samples were chemically etched by immersion in a solution of nitric acid and hydrofluoric acid for $15 \mathrm{sec}$. A two-electrode electrochemical cell was used with the sample as anode and a platinum wire as counter electrode. The applied potential was computer-controlled using a Agilent DC power supply. Anodization was conducted at constant voltage of $15 \mathrm{~V}$ or $25 \mathrm{~V}$ for $1 \mathrm{~h}$ at room temperature. A 1 mol.L $\mathrm{L}^{-1} \mathrm{H}_{3} \mathrm{PO}_{4}$ electrolyte with an addition of $0.3 \mathrm{wt} \% \mathrm{HF}$ was used. A magnetic stirrer was employed during the anodization to avoid formation of bubbles on the electrode surface. After the anodization the samples were rinsed in deinonized water and dried with a heat gun.

The $\mathrm{TiO}_{2}$ nanotubes morphology was analyzed by scanning electron microscopy (SEM) and atomic force microscopy (AFM) in contact mode. The average diameter was calculated after the image acquisition using Image J software measuring 50 nanotubes in three regions of each sample. Structure was evaluated by Raman spectroscopy, using a $532 \mathrm{~nm}$ laser. The elastic modulus was obtained from the Oliver and Pharr method using instrumented indentation tests. A spherical tip (100 $\mu \mathrm{m}$ diameter) was used and the applied loads ranged from $0.10 \mathrm{mN}$ to $100 \mathrm{mN}$ in 8 loading/unloading cycles or $20 \mathrm{mN}$ in one cycle. A Ti polished sample was used as reference to the nanoindentation test.

\section{RESULTS AND DISCUSSIONS}

\subsection{Chronoamperometric curve of obtainment}

Current profile of anodic oxidation is show in Figure 1. It's possible to observe that initially the current density decrease (region I), due to thickening of oxide that act as barrier layer, for both applied voltage. Around $150 \mathrm{sec}$ there is an increase in current density (region II) caused by the nanotube formation, more pronounced for $25 \mathrm{~V}$ than for $15 \mathrm{~V}$, that increase the reactive area subject to anodization. Finally, the curve enters in a steady-state (region III) originated by the balance between oxide growth and dissolution caused by fluoride ions. The current density behavior is in accordance with literature and it is believed that region III is greater for samples anodized at $25 \mathrm{~V}$ due to the higher ions migration through the $\mathrm{TiO}_{2}$ oxide [12], [14]. 


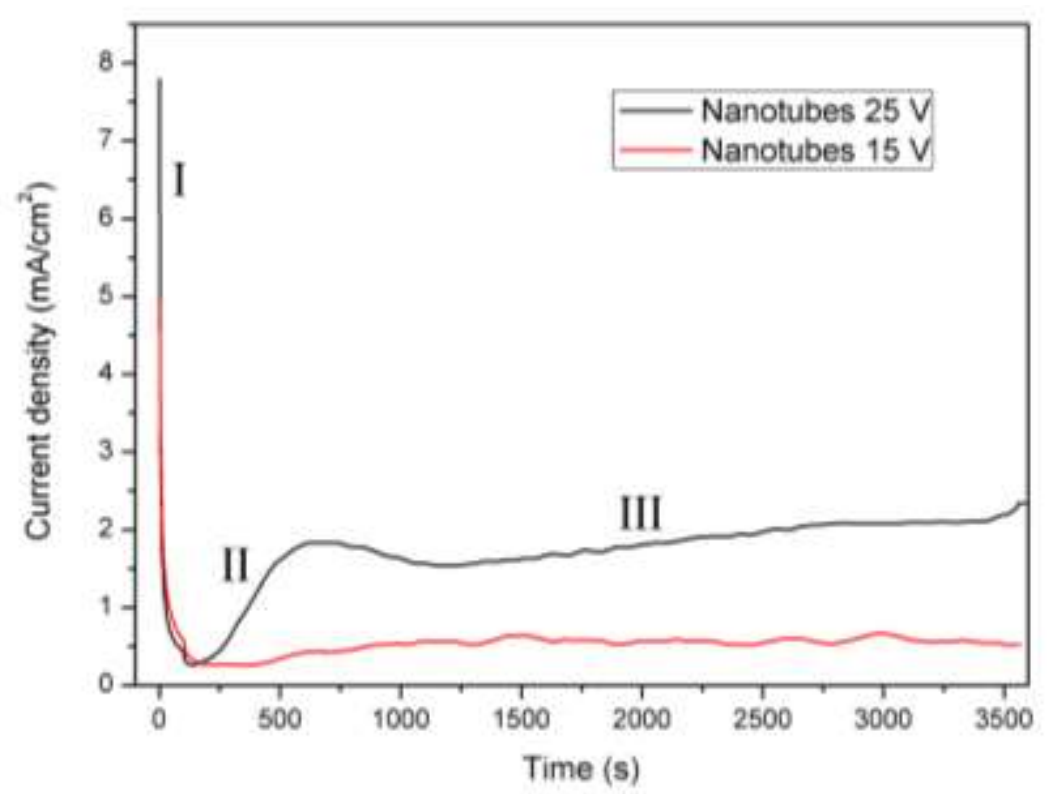

Figure 1: Current densities as function of time during anodization of $\mathrm{TiO}_{2}$ nanotubes obtained at $15 \mathrm{~V}$ and $25 \mathrm{~V}$.

\subsection{Morphological features}

Figure 2 shows an AFM image of the nanotubes anodized at $25 \mathrm{~V}$. It's possible to observe that the nanotubes tops were not on the same level, probably due to the initial roughness. AFM analyses prove to be adequate to observe the topography, but it was not possible to measure diameter and roughness due to the tip convolution, consequence of tip geometry. As a consequence, this image provides just a qualitative view of the nanotopography.

Morphology analysis of $\mathrm{TiO}_{2}$ nanotubes shows that anodization processes lead to a highly ordered nanotube layer, self-organized and perpendicularly disposed over the substrate. SEM images show the top-view of $\mathrm{TiO}_{2}$ nanotubes obtained under $25 \mathrm{~V}$ (Figure 3) and under $15 \mathrm{~V}$ (Figure 4). $\mathrm{TiO}_{2}$ nanotubes diameter is affected by the applied potential. Samples anodized under $15 \mathrm{~V}$ and $25 \mathrm{~V}$ showed inner diameters of $66 \pm 9 \mathrm{~nm}$ and $131 \pm 22 \mathrm{~nm}$ respectively. Since only the applied potential was changed during the anodization tests, it is possible to conclude, in accordance with literature, that the average diameter depends on the applied potential.

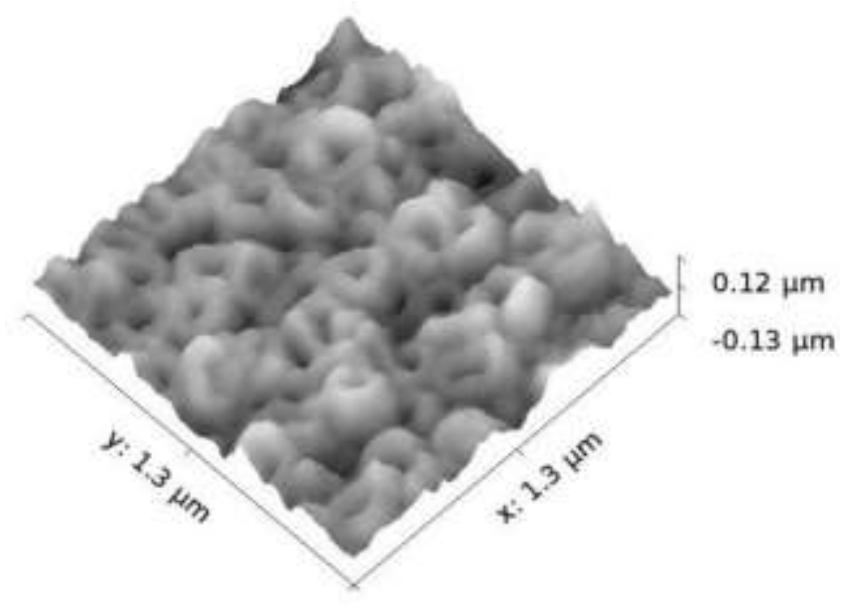

Figure 2: AFM image of $\mathrm{TiO}_{2}$ nanotubes grown at $25 \mathrm{~V}$ obtained by contact mode. 


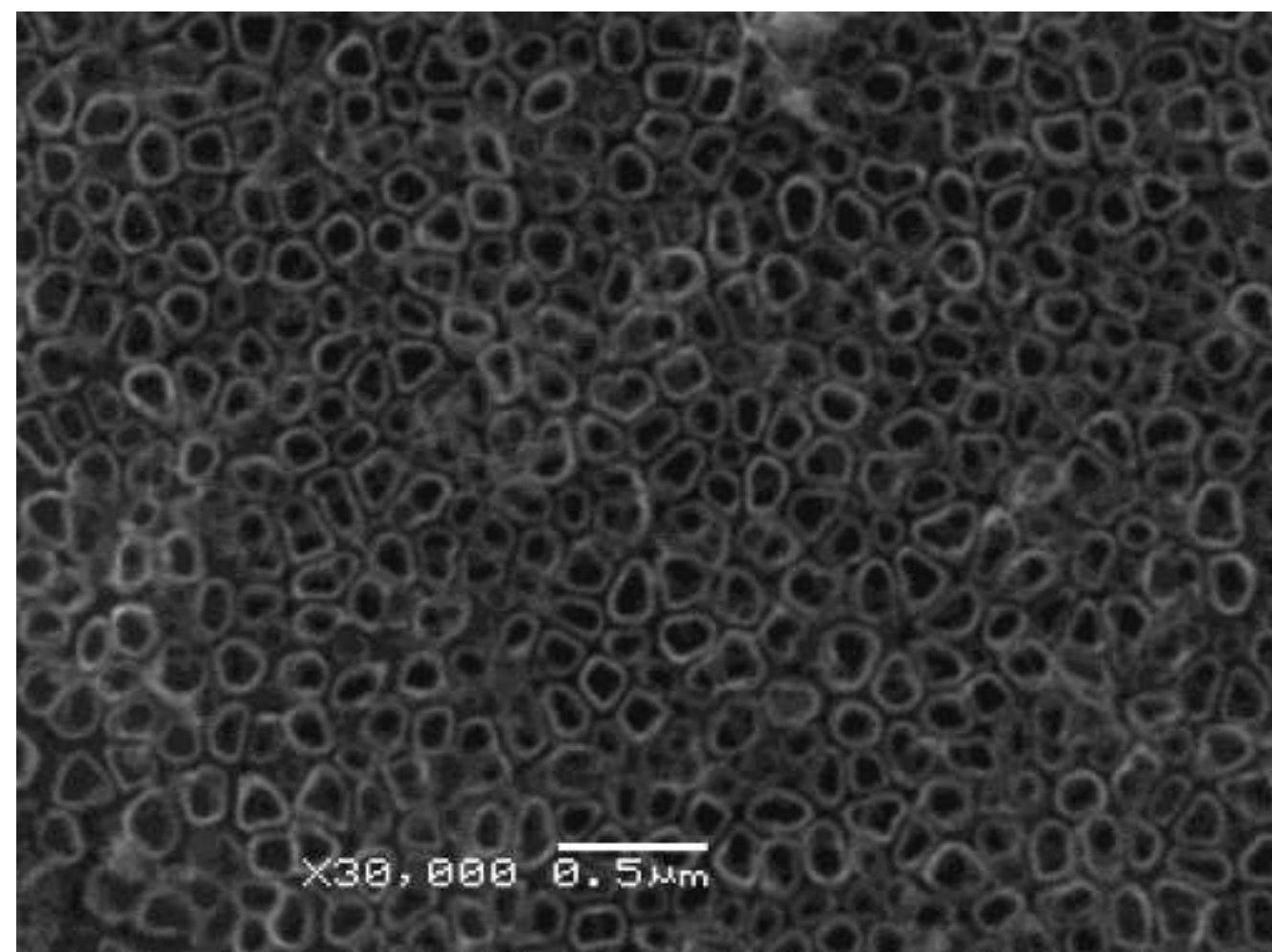

Figure 3: SEM top view images of $\mathrm{TiO}_{2}$ nanotubes grown at $25 \mathrm{~V}$.

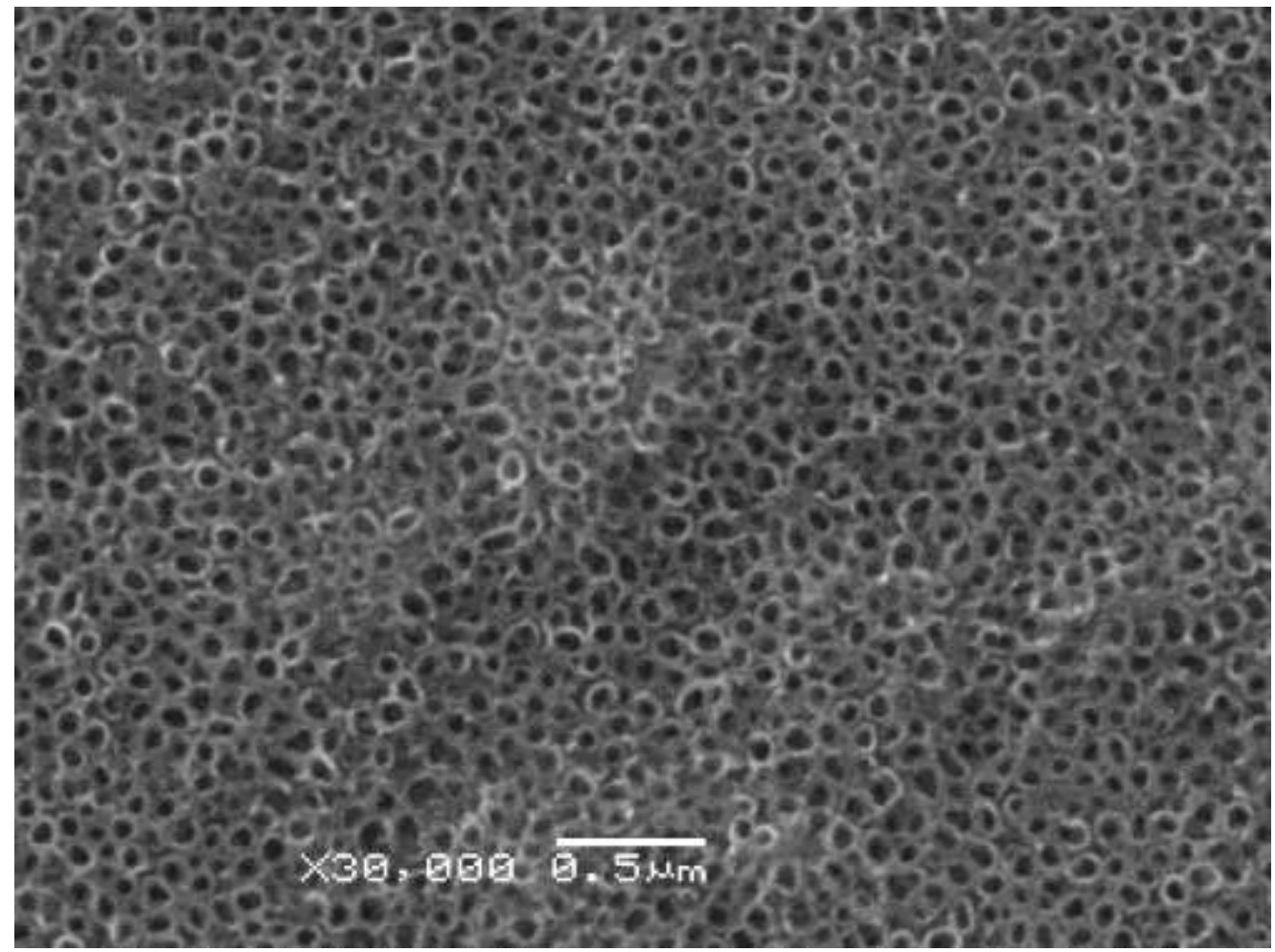

Figure 4: SEM top view images of $\mathrm{TiO}_{2}$ nanotubes grown at $15 \mathrm{~V}$.

\subsection{Crystallinity}

The Raman spectra of both samples is presented in figure 5. No peaks are observed to the titanium substrate, whereas for the nanotube layer obtained at $25 \mathrm{~V}$ it is possible to observe characteristic peaks of anatase phase 
according to RRUFF project. Nanotubes obtained at $15 \mathrm{~V}$ exhibit a broad band instead of well defined peaks. Previous data in literature reported the absence of Raman peaks in porous titanium layers obtained at $20 \mathrm{~V}$ due to the low layer thickness [15].

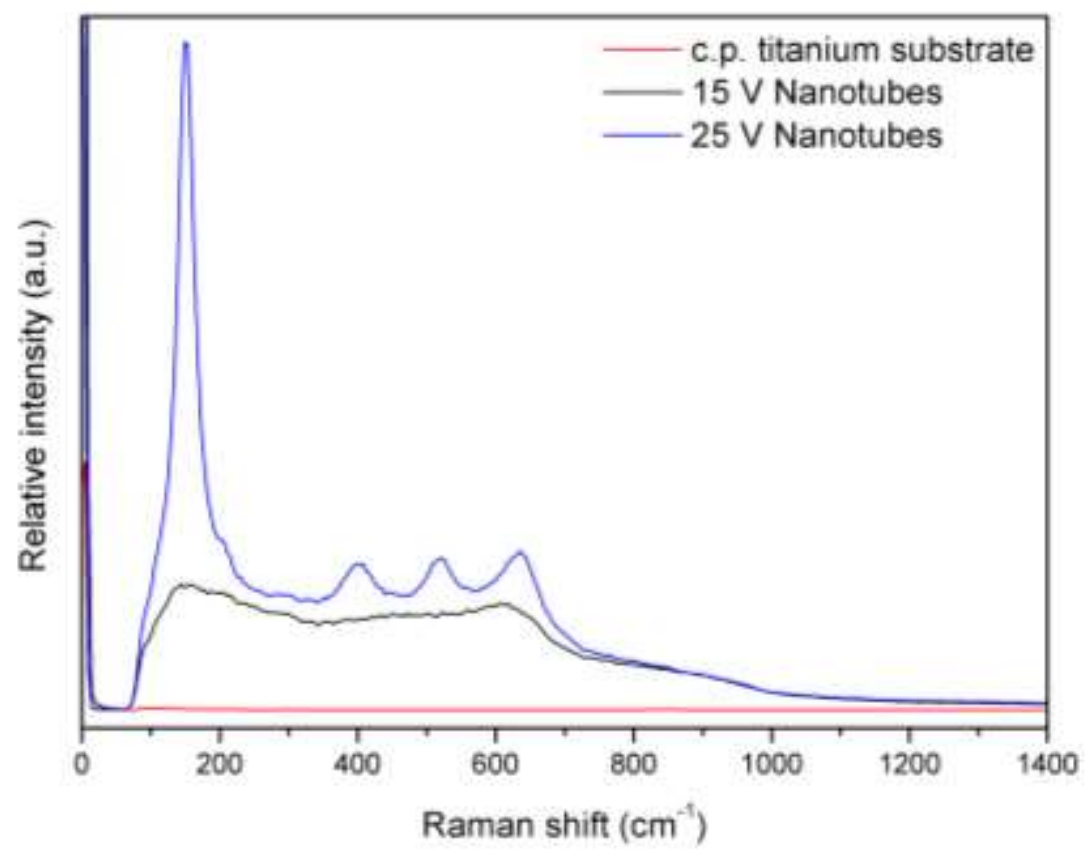

Figura 5: Raman spectra of titanium substrate and nanotube layers obtained at 15 and $25 \mathrm{~V}$.

The dotted blue line on Figure 6a corresponds to the elastic modulus of untreated Ti sample. After the anodization process it was repeated the indentation tests and the results are the black and red dots, to nanotubes obtained under $15 \mathrm{~V}$ and $25 \mathrm{~V}$, respectively. On this test it was performed 8 loading/unloading cycles of indentation, where the maximum load applied was $100 \mathrm{mN}$. As even the small irregularities influence on indentation test, resulting in large deviations, the graphs presented here are useful for comparison but are not quantitative results. Both nanotubes layers show an increase on elastic modulus as the contact depth becomes higher. This behavior is caused by the substrate influence. No difference is observed between the values measured for both nanotubes layers and the amount of anatase phase seems not to be significant to the nanotube elastic modulus.

Literature reports show that the indentation could lead to densification, caused by the collapse of nanotubes under pressure, resulting in results variation [16]. Therefore, other tests were performed using just one loading/unloading cycle and a lower load, $20 \mathrm{mN}$. The results are presented in Figure 6(b), where it is possible to observe that both nanotubes elastic modulus values are lower than that of untreated Ti.

a)

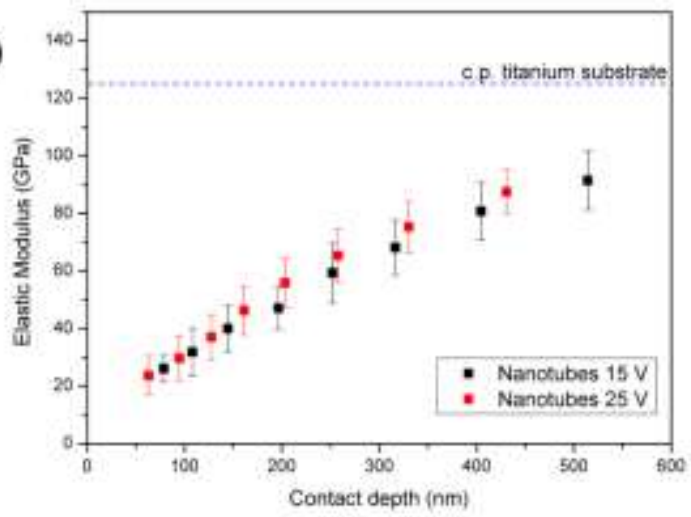

b)

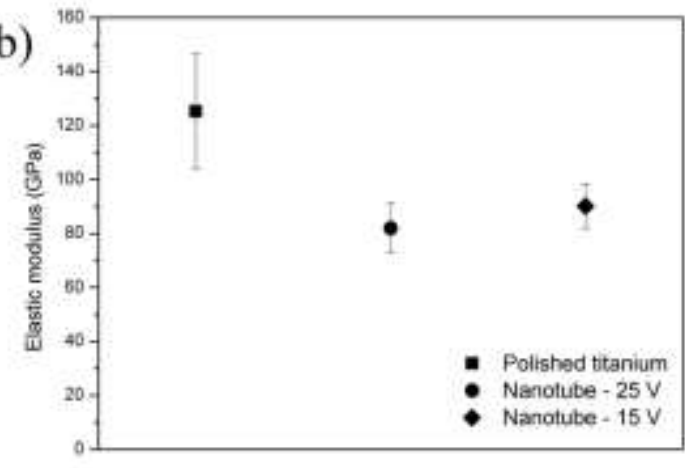


Figure 5: (a) Elastic modulus profile of $\mathrm{TiO}_{2}$ nanotubes anodized at $15 \mathrm{~V}$ (black points) and anodized at 25V (red points) in comparison with titanium reference (blue dotted lines), It's was used 8 loading/unloading cycles with maximum load of $100 \mathrm{mN}$ (b) Elastic modulus for one loading/unloading cycle with load of $20 \mathrm{mN}$.

\section{CONCLUSIONS}

It was possible to obtain nanotubes by anodic oxidation using a 1 mol. $\mathrm{L}^{-1} \mathrm{H}_{3} \mathrm{PO}_{4}+0.3$ wt $\%$ HF electrolyte and the nanotube diameter was defined by the applied potential. The nanotubes elastic modulus does not exhibited difference between nanotubes obtained at $15 \mathrm{~V}$ and $25 \mathrm{~V}$, but both values are lower than that of untreated $\mathrm{Ti}$. These results demonstrated that it was possible to obtain an improved surface due to a homogeneous $\mathrm{TiO}_{2}$ nanotubes layer that has elastic modulus values adequate to improve osseointegration.

\section{ACKNOWLEDGEMENT}

The present study was supported by Brazilian agencies Capes, CNPq and Fundação Araucária. The authors would like to thank the Centro de Microscopia Eletrônica/UFPR for the SEM facilities.

\section{REFERENCES}

[1] a. W. Miles and S. Gheduzzi, "Basic biomechanics and biomaterials," Surg., vol. 30, no. 2, pp. 8691, Feb. 2012.

[2] R. Van-Noort, "Review Titanium : the implant material of today," J. Mater. Sci., vol. 22, pp. 38013811, 1987.

[3] M. Niinomi and M. Nakai, "Titanium-Based Biomaterials for Preventing Stress Shielding between Implant Devices and Bone.," Int. J. Biomater., vol. 2011, p. 836587, Jan. 2011.

[4] S. Izman, M. R. Abdul-kadir, M. Anwar, E. M. Nazim, R. Rosliza, A. Shah, and M. A. Hassan, "Surface Modification Techniques for Biomedical Grade of Titanium Alloys : Oxidation, Carburization and Ion Implantation Processes," 2006.

[5] S. Oh, C. Daraio, L. Chen, T. R. Pisanic, R. R. Fin, and S. Jin, "Significantly accelerated osteoblast cell growth on aligned TiO 2 nanotubes," 2006.

[6] J. Kunze, L. Müller, J. M. Macak, P. Greil, P. Schmuki, and F. A. Müller, "Time-dependent growth of biomimetic apatite on anodic TiO2 nanotubes," Electrochim. Acta, vol. 53, no. 23, pp. 6995-7003, Oct. 2008.

[7] M. Li, X. Xiao, and R. Liu, "Synthesis and bioactivity of highly ordered TiO2 nanotube arrays," Appl. Surf. Sci., vol. 255, no. 2, pp. 365-367, Nov. 2008.

[8] L. M. Bjursten, L. Rasmusson, S. Oh, G. C. Smith, K. S. Brammer, and S. Jin, "Titanium dioxide nanotubes enhance bone bonding in vivo.," J. Biomed. Mater. Res. A, vol. 92, no. 3, pp. 1218-24, Mar. 2010.

[9] W. Yu, J. Qiu, and F. Zhang, "In vitro corrosion study of different TiO2 nanotube layers on titanium in solution with serum proteins.," Colloids Surf. B. Biointerfaces, vol. 84, no. 2, pp. 400-5, Jun. 2011.

[10] K. C. Popat, M. Eltgroth, T. J. Latempa, C. a Grimes, and T. a Desai, "Decreased Staphylococcus epidermis adhesion and increased osteoblast functionality on antibiotic-loaded titania nanotubes.," Biomaterials, vol. 28, no. 32, pp. 4880-8, Nov. 2007.

[11] a. W. Tan, B. Pingguan-Murphy, R. Ahmad, and S. a. Akbar, "Review of titania nanotubes: Fabrication and cellular response," Ceram. Int., vol. 38, no. 6, pp. 4421-4435, Aug. 2012. 
[12] J. M. Macak, H. Tsuchiya, A. Ghicov, K. Yasuda, R. Hahn, S. Bauer, and P. Schmuki, "TiO2 nanotubes: Self-organized electrochemical formation, properties and applications," Curr. Opin. Solid State Mater. Sci., vol. 11, no. 1-2, pp. 3-18, Feb. 2007.

[13] G. a Crawford, N. Chawla, K. Das, S. Bose, and a Bandyopadhyay, "Microstructure and deformation behavior of biocompatible TiO2 nanotubes on titanium substrate.," Acta Biomater., vol. 3, no. 3, pp. 359-67, May 2007.

[14] L. Sun, S. Zhang, X. W. Sun, and X. He, "Effect of electric field strength on the length of anodized titania nanotube arrays," J. Electroanal. Chem., vol. 637, no. 1-2, pp. 6-12, Dec. 2009.

[15] H.-Y. Si, Z.-H. Sun, X. Kang, W.-W. Zi, and H.-L. Zhang, "Voltage-dependent morphology, wettability and photocurrent response of anodic porous titanium dioxide films," Microporous Mesoporous Mater., vol. 119, no. 1-3, pp. 75-81, Mar. 2009.

[16] G. a Crawford, N. Chawla, K. Das, S. Bose, and A. Bandyopadhyay, "Microstructure and deformation behavior of biocompatible TiO2 nanotubes on titanium substrate.," Acta Biomater., vol. 3, no. 3, pp. 359-67, May 2007. 